\title{
A sobrevivência da arte: novas práticas de coral universitário em tempos distantes
}

\author{
Leonardo Rocha de Almeida ${ }^{1}$ \\ Marcelo Rabello dos Santos ${ }^{2}$
}

\section{RESUMO}

Este relato de experiência apresenta e discute as estratégias adotadas por um coro universitário durante o ano de 2020 no contexto da pandemia de COVID-19. Através do uso de diferentes softwares e plataformas de educação a distância, foram mantidas as atividades musicais do grupo, que é uma ação de extensão universitária. Os resultados artísticos foram divulgados principalmente no YouTube, em que cada uma das oito produções atingiu pelo menos cerca de mil visualizações. Um questionário on-line de avaliação foi preenchido pelos extensionistas, que relataram sobre: i) adaptação ao uso de tecnologia; ii) valorização de realizar atividades durante o distanciamento..

Palavras-chave: Música. Coral universitário. Tecnologia. Extensão universitária.

\footnotetext{
${ }^{1}$ Leonard.rocha@hotmail.com - Univ. Federal de Ciências da Saúde de P. Alegre

2 marcelors@ufcspa.edu.br - Univ. Federal de Ciências da Saúde de P. Alegre
} 


\section{Art Survival: new practices of a university choir in times of social distance}

\section{ABSTRACT}

This experience report presents and discusses the strategies adopted by a university choir during the year 2020 in the context of the COVID-19 pandemic Using various software and distance education platforms, the group, which is a university extension program, managed to maintain its musical activity. The artistic results were released mostly on YouTube, in which each of the eight productions reached at least about a thousand views. An online assessment questionnaire was completed by extension workers, who reported on: i) adaptation to the use of technology; ii) valorization of carrying out activities during the distance.

Keywords: Music. University choir. Technology. Extension program. 
Os tempos da pandemia de COVID-19 têm sido sombrios para cultura brasileira, apesar da mobilização do setor cultural (CALABRE, 2020). A necessidade da adoção de medidas de isolamento social afeta diretamente os grupos corais, na medida em que suas atividades principais - ensaios e apresentações - são desenvolvidas de forma presencial. O contexto da pandemia levou o Coral UFCSPA, um projeto de extensão da Universidade Federal de Ciências da Saúde de Porto Alegre (UFCSPA), a interromper as atividades presenciais em 18 de março de 2020, após a realização de duas semanas de ensaios normais. Coube a um grupo de extensionistas, responsável pela execução do projeto, pensar em como dar continuidade às atividades, atendendo assim o grupo de pessoas já inscritas para participarem do coro ao longo do ano.

O canto coral é uma expressão artística vocal coletiva com preponderante papel no desenvolvimento da cultura musical do ocidente, sendo muitas vezes encarada como metáfora de valores civilizacionais, como discutem Santos e Almeida (2017a). O Coral UFCSPA, que iniciou suas atividades em 2012, vem procurando aproximar a prática coral tradicional dos marcos conceituais extensionistas, e para tanto adota uma abordagem inclusiva: não requer de seus potenciais participantes experiência prévia ou realização de testes seletivos e, em tempos prépandemia, oferecia diversas possibilidades de horário de ensaio, permitindo que os coralistas escolhessem o horário mais conveniente (SANTOS; BRASIL; ALMEIDA, 2017).

Outra característica do trabalho do Coral UFCSPA é processo participativo de escolha do tema do repertório. Ao final de 2019, através de enquete online, foi escolhido o tema Esperança para nortear as escolhas musicais de 2020. A escolha foi anterior, portanto, ao contexto da pandemia, mas vem se mostrando singularmente apropriada para auxiliar na seleção das canções a serem trabalhadas em 2020.

\section{A EDUCAÇÃO A DISTÂNCIA}

Ao pensar sobre o desenrolar das atividades durante o período de distanciamento é necessário olhar para algumas questões referentes a Educação a Distância (EAD). Principalmente sobre a questão dos seus usos e conceitualização dentro do modelo adotado pelo grupo ao qual se faz o relato.

Como discutem Favero e Franco (2006), a EAD tem estruturas específicas e relevância local na sociedade como meio de disseminar o acesso à educação, não podendo ser uma forma precária do modelo presencial. Quando afirmam isso, eles colocam a EAD num local de métodos próprios no que tange ao uso consciente das ferramentas disponíveis nos ambientes de aprendizagem.

Alonso e Silva (2018) destacam que a EAD é um campo de pesquisa em processo de constituição, em que se sobrepõem educação, comunicação e tecnologias. Os autores convidam a lançar sobre a EAD um olhar que, em vez de fixar-se no antagonismo entre o presencial e o nãopresencial, procure aprofundar-se na busca por convergências. Acrescentam que desse processo 
podem surgir oportunidades educacionais que, de fato, democratizem o acesso com qualidade à população.

Desta forma, abre-se espaço para discutir a perspectiva metodológica do Coral UFCSPA em tempos de pandemia não somente em termos da sua excepcionalidade, mas também como uma oportunidade de construir uma abordagem ainda mais inclusiva, permitindo a produção de novos objetos didáticos e produtos artísticos.

\section{MATERIAIS E MÉTODOS}

O ambiente virtual de aprendizagem MOODLE da UFCSPA vem sendo empregado pelo coral desde o início de suas atividades, em 2012, para compartilhar partituras, trilhas de áudio para ensaio e outros recursos de apoio ao aprendizado musical (SANTOS; ALMEIDA, 2017b). As partituras são compartilhadas em formato .pdf e elaboradas empregando o software livre de edição de partituras MuseScore. As trilhas de áudio são elaboradas em separado para cada um dos naipes que constituem o coral, ou seja, sopranos, contraltos, tenores e baixos. São gravadas e editadas empregando o Audacity, um software livre de edição de áudio, através de um microfone (Shure 8700) conectado a um dispositivo de som USB externo (Roland Go:Mixer).

A grande novidade trazida pelos tempos de pandemia em termo de aprendizado do repertório musical, portanto, foi a mudança no papel do moodle, que passou a ser o principal recurso didático do coral ao invés de um auxiliar dos ensaios presenciais. Assim, o fato deste ambiente virtual já fazer parte da rotina dos integrantes, mesmo que de forma subsidiária, foi significativo para a manutenção do trabalho em uma abordagem assíncrona, em que os recursos digitais podem ser reproduzidos - integralmente ou em parte - quantas vezes for desejado, de acordo com a conveniência do usuário. O Coral UFCSPA não adotou a prática de ensaios virtuais, levando em consideração as limitações de sincronia e qualidade de áudio de tais encontros.

Em termos de comunicação com o grande público, foi adotada uma rotina de produção de vídeos de performances coletivas virtuais. Os participantes foram convidados a participar de novas produções virtuais através de uma mensagem enviada por e-mail informando: a músicadesafio a ser estudada e gravada em seu próprio celular ou computador; detalhamento sobre os recursos disponíveis sobre canção em questão no moodle; um prazo final para o aprendizado, gravação e envio de um vídeo contendo a performance musical individual de cada participante. Os participantes estavam cientes de que o envio do vídeo pressupunha a cedência dos direitos de som e imagem ao projeto. Os vídeos individuais foram então editados de forma a constituírem juntos uma única produção audiovisual, o "coral virtual”. As produções resultantes foram disponibilizadas para o grande público através do YouTubei e redes sociaisii.

A primeira produção desse gênero - I Want to Break Free, da banda Queen - teve caráter experimental e contou com a participação de um grupo limitado de coralistas, tendo sido divulgada apenas para os demais participante do grupo. A produção deste vídeo permitiu estabelecer aspectos que seriam doravante empregados, como a necessidade de produzir independentemente som e imagem e reuni-los tão somente ao final do processo de produção. A edição de som vem sendo realizada também com o Audacity. A edição de vídeo - e reunião final de vídeo e áudio - vem sendo realizada com o software livre OpenShot. 
Os resultados são apresentados em duas partes. A primeira diz respeito à disseminação das produções artísticas do projeto junto ao público, que ocorrem através de vídeos, levando em conta a impossibilidade da realização de eventos musicais presenciais. A segunda relaciona-se com a caracterização dos coralistas envolvidos no projeto, que - preservando os preceitos éticos - não são identificados no tratamento dos dados.

Tabela 1: Produções virtuais do Coral UFCSPA em 2020

\begin{tabular}{c|c|c|c}
\hline Data & Canção & Participantes $^{\text {Visualizações }^{\text {iii }}}$ \\
\hline $31 / 03$ & I Want to Break Free (Queen) & 4 & NA $^{\text {iv }}$ \\
\hline $09 / 04$ & Amanhã (Guilherme Arantes) & 51 & 4.448 \\
\hline $08 / 05$ & Sonho Meu (Dona Ivone Lara) & 68 & 1.234 \\
\hline $05 / 06$ & Benke (Milton Nascimento) & 59 & 1.744 \\
\hline $13 / 07$ & Wind of Change (Scorpions) & 61 & 1.700 \\
\hline $18 / 09$ & Semeadura (Ramil / Fogaça) & 69 & 1.289 \\
\hline $13 / 11$ & E Vamos à Luta (Gonzaguinha) & 51 & 956 \\
\hline $21 / 12$ & Amor pra Recomeçar (Frejat / Barros / Sta. Cecília) & 53 & 909 \\
\hline
\end{tabular}

Fonte: Elaborado a partir de dados do projeto.

A Tabela 1 apresenta um sumário dos vídeos do Coral UFCSPA produzidos entre março e dezembro, no contexto da pandemia. São apresentadas as datas de lançamento em 2020 no YouTube, as canções trabalhadas, o número de coralistas que enviou contribuições individuais em vídeo e o número de visualizações na plataforma original. Não são contabilizadas reproduções em outras plataformas e outras formas de difusão.

O vídeo mais visualizado é Amanhã, cerca de quatro vezes mais assistido que os demais. Uma possível razão para o alcance dessa produção é o relativo ineditismo do formato "coral virtual" por ocasião de seu lançamento, tendo sido inclusive exibida no programa televisivo local Jornal do Almoço em 16 de abril. No momento da redação deste artigo, vídeos musicais coletivos já estão sendo amplamente adotados como parte da estratégia de sobrevivência de diversos outros grupos corais. Sem perder de vista o tema esperança, as canções Sonho Meu, Benke e Semeadura tiveram seus lançamentos vinculados a datas comemorativas, respectivamente o Dia das Mães (10/05), o Dia do Meio Ambiente (05/06) e a Revolução Farroupilha (20/09).

No mês de agosto os participantes foram convidados a preencher um formulário online de avaliação das atividades até então. Foi respondido por 71 participantes do Coral UFCSPA. sendo que esse número é considerado aqui como correspondendo ao total de participantes durante o período de excepcionalidade decorrente da pandemia. De acordo com a Figura 1, que apresenta a distribuição etária dos participantes, 36\% dos participantes são idosos nascidos antes de 1959, mostrando um bom engajamento dessa faixa etária com as atividades em formato virtual. 


\section{Figura 1: Distribuição etária dos participantes}

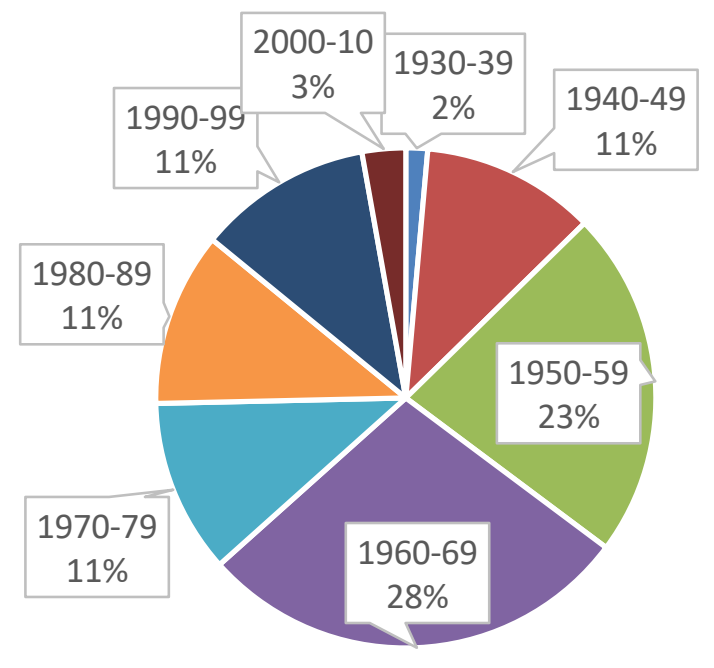

\section{Fonte: Dados do projeto}

Esse é uma característica importante, pois tratando-se de um coral universitário, seria esperado que houvesse uma parcela de jovens mais próxima, mas que figura em $14 \%$ dos nascidos de 1990 até o presente.

Como mostra a Figura 2, a maioria dos participantes declara-se adaptado ao modelo virtual de participação no coral. Interessantemente, o número de participantes que assinalou dificuldades tecnológicas é ainda menor do que aquelas e aqueles que sentem timidez em relação a voz e/ou imagem.

\section{Figura 2: Engajamento nas atividades à distância}

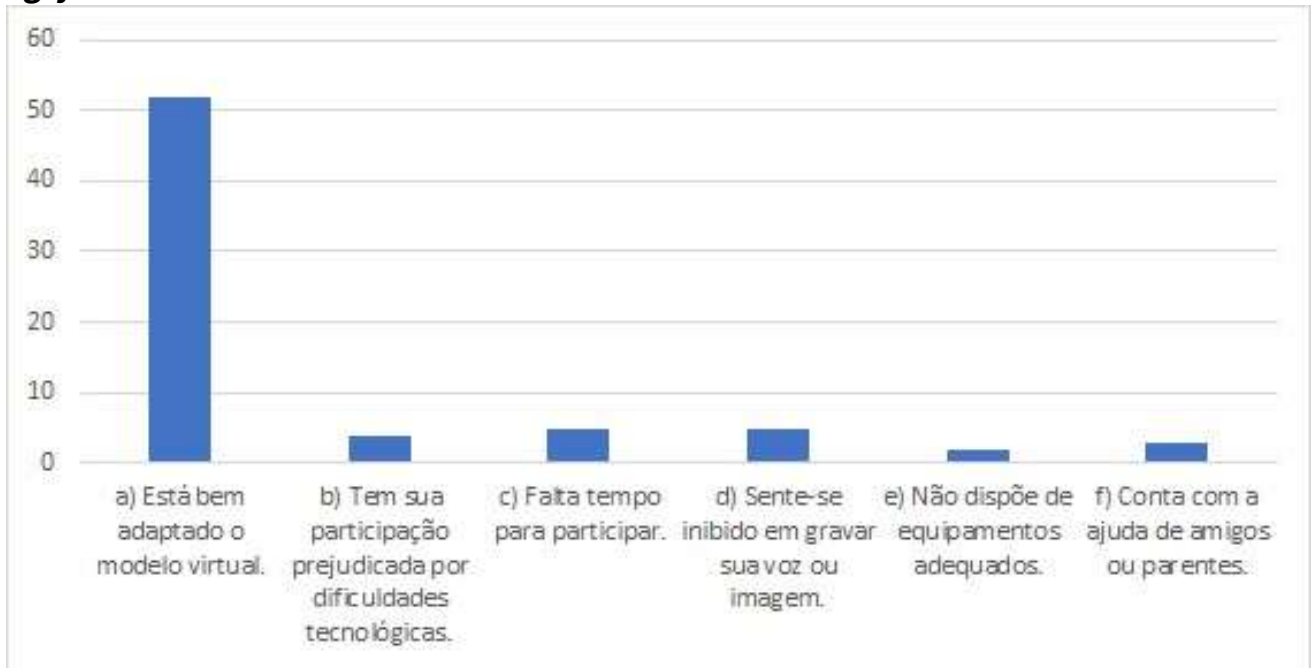

Fonte: Elaborado a partir de dados do projeto

A Tabela 2 apresenta a distribuição dos participantes por naipe vocal, sendo soprano e contralto os naipes femininos e tenor e baixo os naipes masculinos. O Coral UFCSPA também incorpora vozes femininas ao naipe dos tenores, que é tradicionalmente masculino. Estas participantes estão indicadas no naipe das tenorinas. 
Tabela 2: Distribuição dos participantes por naipe

\begin{tabular}{l|l|l}
\hline Naipe & $\mathbf{N}$. & $\%$ \\
\hline Sopranos & 18 & $25.35 \%$ \\
\hline Contraltos & 36 & $50.70 \%$ \\
\hline Tenorinas & 2 & $2.82 \%$ \\
\hline Tenores & 9 & $12.68 \%$ \\
\hline Baixos & 6 & $8.45 \%$ \\
\hline
\end{tabular}

Fonte: Elaborado a partir de dados do projeto

A partir dos dados é possível perceber que o grupo foi composto majoritariamente por vozes femininas, com $78.87 \%$ do total de participantes.

A Figura 3 apresenta a concordância dos coralistas em relação a três afirmações através de escala Likert (LIKERT, 1932). A maior concordância plena (84,51\%) é com a afirmação que o coral continua, através de suas ações virtuais, a divulgar seu trabalho junto ao público - embora para esta questão haja também a maior proporção de respostas neutras. Quanto às demais questões, quando somadas as respostas positivas de "concordo parcialmente" e "concordo plenamente" se tem mais de $94 \%$ da opinião do grupo. As repostas indicam que os participantes mantêm seu engajamento com o projeto - mesmo sem a realização de ensaios síncronos regulares - e reforçam a ideia de que as ações desenvolvidas adquiriram um sentido não previsto inicialmente: o de aliadas em um momento de mudanças bruscas no estilo de vida.

Figura 3: Percepções dos participantes sobre as atividades à distância

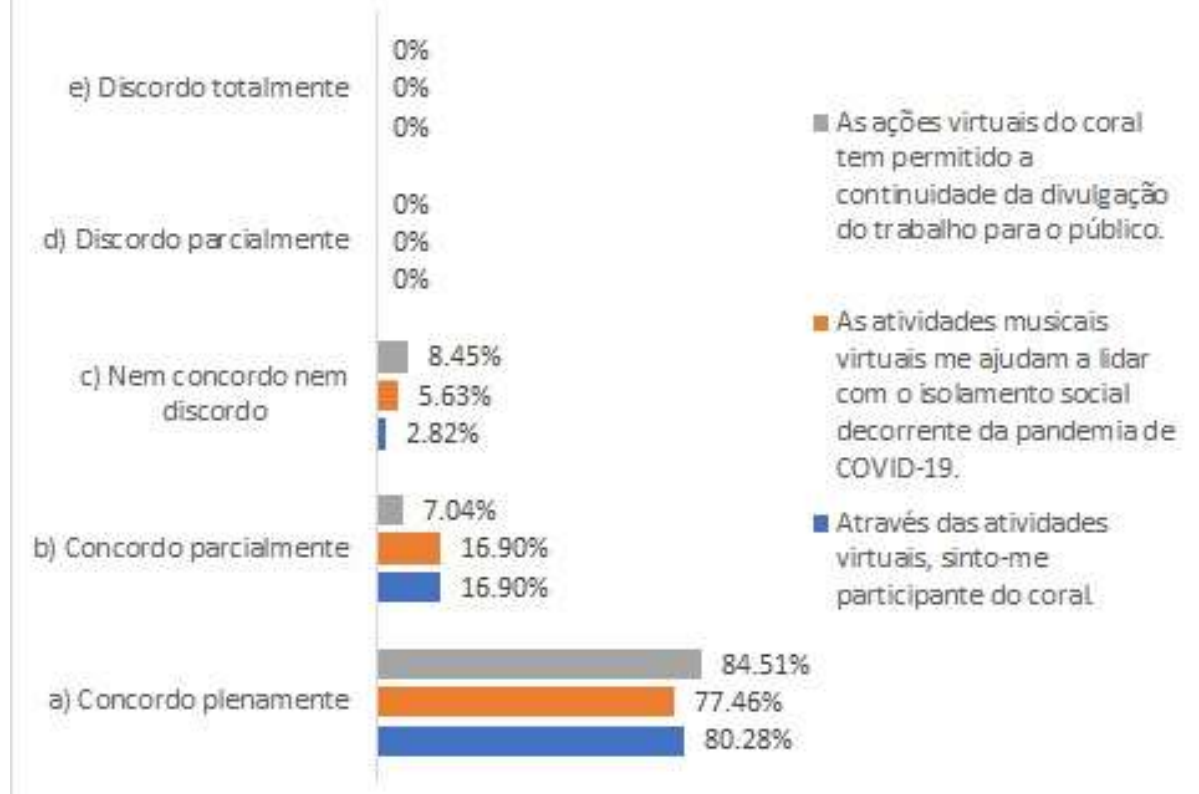

\section{Fonte: Elaborado a partir de dados do projeto}

Como se viu, no contexto da pandemia a estratégia adotada pelo Coral UFCSPA foi a de priorizar o aprendizado assíncrono através do moodle. Recursos didáticos já disponíveis foram ressignificados a partir das novas necessidades dos usuários: as gravações de ensaio, 
tradicionalmente empregadas como auxiliares do aprendizado presencial, passaram a ser empregadas como base de apoio musical à gravação dos vídeos individuais. Essa continuidade metodológica parece ter permitido que a maioria dos participantes se adaptasse ao modelo EAD, inclusive os mais idosos.

A questão do aprendizado musical através de recursos virtuais vem sendo discutida pela literatura nos últimos anos, mesmo antes da eclosão da pandemia. Para Johansen (2014), o cenário da educação musical corre o risco de cindir-se em dois polos: o formal, constituído pelas práticas de ensino musicais presenciais em um contexto institucional, e o informal, constituído por práticas de autoensino tornadas possíveis pelo crescente corpo de material disponível na web e que em um primeiro momento dispensariam a figura do instrutor musical - seja o professor, o regente etc. Para o autor, seria possível transcender essa dicotomia, e o papel do tutor musical poderia ser visto, em certos contextos, mais como o de um negociador de significados do que o de um instrutor musical em sentido estrito. A visão de Johansen (2014) pode ser relacionada, assim, ao caminho trilhado neste momento pelo Coral UFCSPA, em sua busca por convergências e oportunidades. Os organizadores do projeto confiam aos participantes materiais destinados ao autoensino, ao mesmo tempo em que se preocupam em proporcionar experiências musicais relevantes e significativas para o período que vivemos.

As recentes produções em vídeo do Coral UFCSPA, neste momento a principal forma de interação artística com o grande público, também podem ser relacionadas com tendências de mudança já existentes no cenário pré-pandêmico. Hesmondhalgh e Meier (2016) descrevem a crescente digitalização da música, que vem migrando do mundo das performances ao vivo para o mundo das gravações, tendo passado por vitrolas, cassetes, CDs, iPods e finalmente chegado às plataformas de streaming como o Spotify e o YouTube. Volgsten e Pontara (2017) enxergam esse processo negativamente, como o nascimento de uma cultura sonora solipsista, potencialmente alienante, em que a audição solitária - mediada pela tecnologia - é a norma, e as práticas musicais coletivas a exceção.

Neste sentido, é preocupante o fato de o Coral UFCSPA, ao longo de 2020, não ter agregado um número significativo de novos participantes, embora tenha preservado boa parte dos inscritos presencialmente no início do ano. A ênfase na continuidade metodológica pode ser também vista como uma limitação: incentiva a permanência daqueles já familiarizados com os processos, mas não providencia ferramentas específicas para aqueles que desejam que iniciar-se no canto coral. O próximo desafio do Coral UFCSPA, conforme preconizado por Favero e Franco (2006), é construir objetos de aprendizagem inovadores, próprios ao cenário do canto coral em modalidade a distância.

\section{CONSIDERAÇÕES FINAIS}

Por seu compromisso com o fazer musical coletivo, o movimento coral, antes da pandemia, mostrava-se refratário às novas tendências contemporâneas da cultura musical e do ensino da música. O Coral UFCSPA, no afã de manter suas atividades, conferiu centralidade aos processos de aprendizagem a distância e criou o seu próprio canal no YouTube, validando assim as práticas de autoensino informais. Enquanto o público estimado para as apresentações e concertos de 
2019 do Coral UFCSPA foi de pouco mais de duas mil pessoas, em 2020 as produções já contam ultrapassaram as dez mil visualizações, como apresentado no decorrer do texto. Naturalmente, não se pode comparar plenamente a experiência de assistir a uma performance ao vivo com a de assistir a um vídeo, mas a adoção emergencial do YouTube como plataforma principal de comunicação com o público perece ter conferido às produções do Coral UFCSPA maior capilaridade social, assim como a possibilidade de registro de suas produções ao longo do tempo. Nesse sentido, as novas práticas pelo Coral UFCSPA têm contribuído para um maior acesso à música coral e difusão da cultura musical.

A julgar pela trajetória do Coral UFCSPA, é bem possível que algumas das transformações que o movimento coral vem sofrendo em decorrência da pandemia de COVID-19 correspondam a uma necessária mudança de rumo e venham a perpetuar-se. Mesmo Volgsten e Pontara (2017) não são pessimistas quanto ao futuro da cultura musical, e enxergam a possibilidade de que o desejo de compartilhar as experiências musicais, aliado à tecnologia, possa finalmente vir a dissolver as bolhas sonoras individuais. Um novo canto coral, mais sintonizado com os tempos, talvez venha a fazer parte deste processo.

\section{REFERÊNCIAS}

ALONSO, K. M.; SILVA, D. G. A educação a distância e a formação on-line: o cenário das pesquisas, metodologias e tendências. Educ. Soc., Campinas, v. 39, n. 143, p. 499-514, jun., 2018. DOI: 10.1590/es0101-73302018200082.

CALABRE, L. A arte e a cultura em tempos de pandemia: os vários vírus que nos assolam. Extraprensa, v.13, n.2, p.7-21, jan./jun., 2020. Disponível em:

http://www.periodicos.usp.br/extraprensa/article/view/170903/162152 Acesso em: 30 out. 2020.

FAVERO, R. V. M. FRANCO, S. R. K. Um estudo sobre a permanência e a evasão na Educação a Distância. RENOTE, v. 4, n. 2, dez, 2006.

HESMONDHALGH, D.; MEIER, L. M. What the digitalisation of music tells us about capitalism, culture and the power of the information technology sector. Information, Communication \& Society, v. 21, n. 11, p. 1555-1570, 2018. DOI: 10.1080/1369118X.2017.1340498.

JOHANSEN, G. Sociology, music education, and social change: The prospect of addressing their relations by attending to some central, expanded concepts. Action, Criticism, and Theory for Music Education, v. 13, n. 1, p. 70-100, 2014. Disponível em: http://act.maydaygroup.org/articles/Johansen13_1.pdf. Acesso em: 31 out. 2020 .

LIKERT, R. A technique for the measurement of attitudes. Archives of Psychology. v. 22, n. 140, p. 44-53, 1932.

SANTOS, M. R.; ALMEIDA, L. R. Coral UFCSPA: Cinco Anos de Inquietação. In: IV Encontro de Pesquisas Históricas da Pontifícia Universidade Católica do Rio Grande do Sul. Anais[...] Porto Alegre: PPGH/PUCRS, 2017a. Disponível em: https://editora.pucrs.br/edipucrs/acessolivre//anais/ephis/assets/edicoes/2017/arquivos/1.pdf. Acesso em: 29 out. 2020. 
SANTOS, M. R.; ALMEIDA, L. R. Coral UFCSPA e o uso das tecnologias para uma inclusão na contemporaneidade. Revista Redin, v. 6, n. 1, 2007b. Disponível em:

http://seer.faccat.br/index.php/redin/article/view/629. Acesso em: 30 out. 2020.

SANTOS, Marcelo Rabello; BRASIL, A. C.; ALMEIDA, Leonardo Rocha. Coral UFCSPA: Cinco anos de música e cidadania. In: $35^{\circ}$ Seminário de Extensão Universitária da Região Sul - Área temática: Cultura. Anais... Foz do Iguaçu: Proex/UNILA, 2017 Disponível em: https://dspace.unila.edu.br/bitstream/handle/123456789/ 3818/SEURS_939-944.pdf?sequence=1\&isAllowed=y. Acesso em: 30 out. 2020.

VOLGSTEN, U.; PONTARA, T. Domestic space, music technology and the emergence of solitary listening: tracing the roots of solipsistic sound culture in the digital age. Svensk tidskrift för musikforskning, v. 99, n. 1, p. 105-123, 2017. Disponível em: https://oru.diva-

portal.org/smash/get/diva2:1172224/FULLTEXT01.pdf. Acesso em: 29 out. 2020.

\footnotetext{
i https://www.youtube.com/c/CoralUFCSPA

ii https://www.facebook.com/coralufcspa

iii Total de visualizações dos vídeos oficiais do coral no YouTube em 31/01/2021.

iv Não adicionado
} 